\title{
A case of Alagille syndrome complicated by intraocular lens subluxation and rhegmatogenous retinal detachment
}

This article was published in the following Dove Press journal:

Clinical Ophthalmology

16 July 2013

Number of times this article has been viewed

\author{
Masanori Fukumoto \\ Tsunehiko Ikeda \\ Tetsuya Sugiyama \\ Mari Ueki \\ Takaki Sato \\ Eisuke Ishizaki
}

Department of Ophthalmology, Osaka Medical College, Takatsuki City, Japan

\begin{abstract}
This case report describes a case of Alagille syndrome with developing intraocular lens subluxation and rhegmatogenous retinal detachment 4 years after cataract surgery. A 15-year-old female patient with Alagille syndrome-associated cataracts in both eyes underwent phacoemulsification aspiration and intraocular lens implantation. Four years postoperative, intraocular lens subluxation developed in her left eye. For treatment, extraction of the dislocated intraocular lens, anterior vitrectomy, and intraocular lens fixation was performed. Three weeks later, the patient developed rhegmatogenous retinal detachment, which was well-treated by pars plana vitrectomy. Cataract surgery needs to be performed carefully in patients with Alagille syndrome due to the weakness of the zonule of Zinn. Careful postoperative observation is necessary for patients with Alagille syndrome who have undergone intraocular surgery in order to facilitate early detection of a possible rhegmatogenous retinal detachment.
\end{abstract}

Keywords: Alagille syndrome, cataract, retina, surgery

\section{Introduction}

Alagille syndrome is an autosomal dominant multiple malformation disorder associated with hypoplasia of intrahepatic bile ducts, a characteristic facial appearance, and abnormalities of the cardiovascular system and vertebra. ${ }^{1}$ Variable ocular anomalies also occur with this syndrome, most commonly comprising posterior embryotoxon, chorioretinal degeneration, and cataract. ${ }^{2-5}$ In this case report, we performed phacoemulsification aspiration and intraocular lens implantation for a case of Alagille syndrome causing cataracts in both eyes. Postoperative complications such as intraocular lens subluxation and rhegmatogenous retinal detachment developed 4 years after surgery.

\section{Case presentation Case}

A 15-year-old female.

\section{Chief complaint}

Visual impairment in both eyes.

\section{Clinical history}

A 15-year-old female patient with Alagille syndrome was referred from the pediatric hepatology department of our Osaka Medical College for investigation of visual loss that had occurred in both eyes. Examination of the patient's anterior segment revealed bilateral posterior subcapsular cataracts (Figure 1), and examination of the dilated 


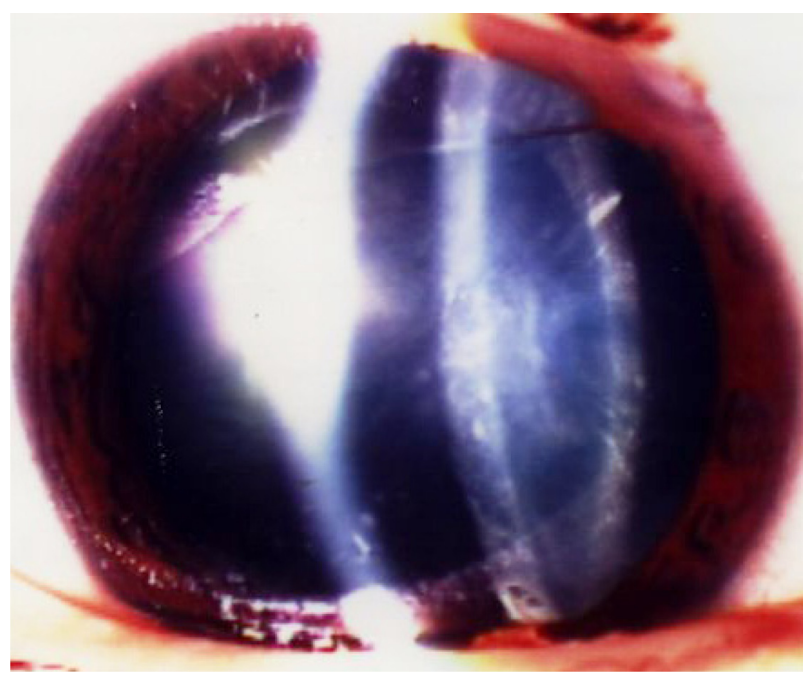

Figure I Slit lamp microscopy images of the patient's left eye obtained prior to cataract surgery.

Notes: Posterior subcapsular cataracts are visible in the image.

fundus revealed the existence of a giant optic disc and mild chorioretinal atrophy (Figure 2). The patient's corrected visual acuity (VA) was 20/200 in her right eye and 30/200 in her left eye. The axial lengths in the patient's right and left eye were $22.94 \mathrm{~mm}$ and $23.07 \mathrm{~mm}$, respectively. The patient did not report any diplopia, and the movement of both eyes was found to be normal.

In March 2000, we performed phacoemulsification aspiration and intraocular lens implantation for both of her eyes.

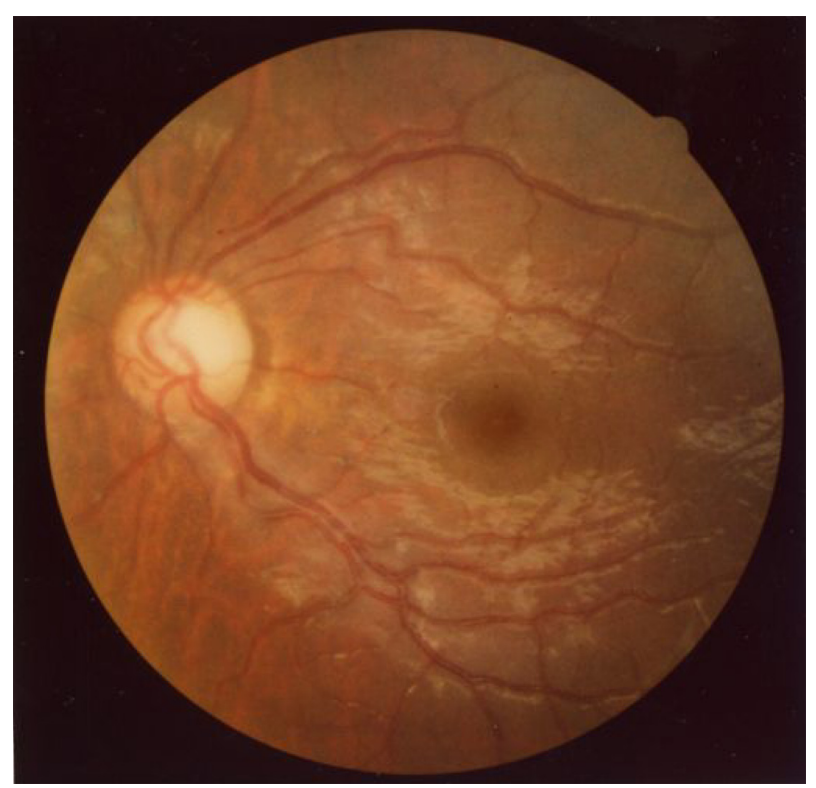

Figure 2 Color fundus photograph of the patient's left eye, obtained prior to cataract surgery.

Note: Color fundus photograph of the patient's left eye demonstrating giant optic disc and mild chorioretinal atrophy.
Postoperatively, VA in the patient's right and left eyes improved to $20 / 70$ and 20/30, respectively.

In-the-bag fixation of the intraocular lens was achieved without damage of the capsule or zonule of Zinn, but fragility of the zonule was apparent. Following surgery, serial observations were performed in our department. The patient became aware of decreased VA in the left eye beginning in January 2004 and returned to our hospital. Upon examination of the patient, subluxation of the intraocular lens was diagnosed in her left eye (Figure 3), and she was hospitalized for surgery on March 19, 2004.

\section{Previous history}

Serial observations were performed under a diagnosis of intrahepatic bile duct hypoplasia with Alagille syndrome, in the pediatric section of our hospital from October 1988.

\section{Family history}

The patient's mother had also been diagnosed with Alagille syndrome.

\section{Clinical course after hospitalization}

Extraction of a dislocated intraocular lens, anterior vitrectomy, and intraocular lens fixation at the ciliary sulcus were performed on March 19, 2004. The operation was concluded without any particular complications, and the patient's postoperative VA recovered to 20/30. However, she noted decreased VA again on June 7, 2004 and subsequently presented to our hospital. Upon examination, her left eye showed bullous retinal detachment, and we performed vitreous surgery on June 11, 2004. Surgical procedures comprised subtotal vitrectomy, pneumatic replacement of the retina, endophotocoagulation, transscleral cryopexy,

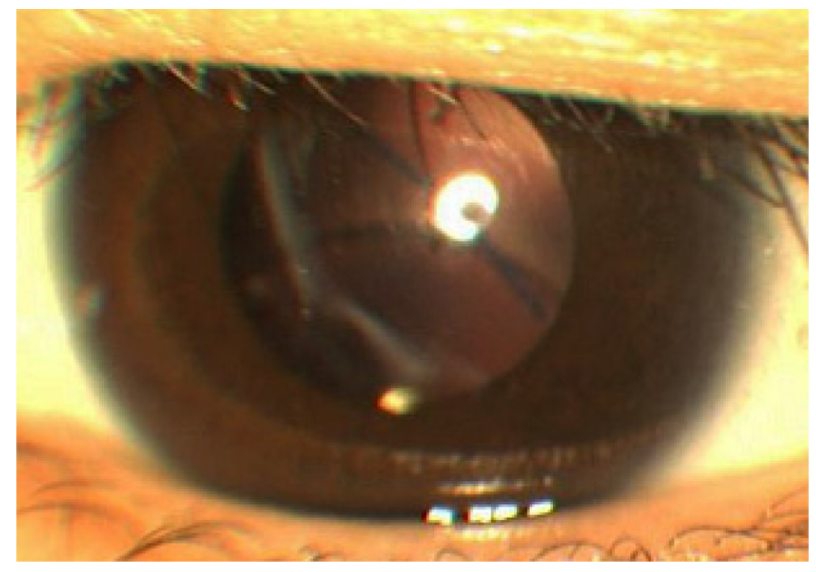

Figure 3 Slit lamp microscopy image of the patient's left eye.

Notes: Slit lamp microscopy image of the patient's left eye obtained 4 years after cataract surgery. Intraocular lens subluxation can be seen in the image. 
peripheral encircling with a silicone band (\#240; MIRA, Inc, Waltham, MA, USA), and gas tamponade with $14 \%$ C3F 8 gas. During the operation, a small retinal tear was detected in the peripheral area of the upper quadrant. As for the vitreous humor, hydropic degeneration was marked in comparison with the patient's age (Figure 4). Postoperatively, the patient's retina was well-attached and her corrected VA improved to $20 / 50$.

\section{Discussion}

Posterior embryotoxon, chorioretinal degeneration, optic disk abnormality, posterior subcapsular cataract, microphthalmia, keratoconus, and corneal opacity have been reported as ocular complications associated with Alagille syndrome. ${ }^{2-5}$ Traboulsi et al described keratoconus and corneal opacity

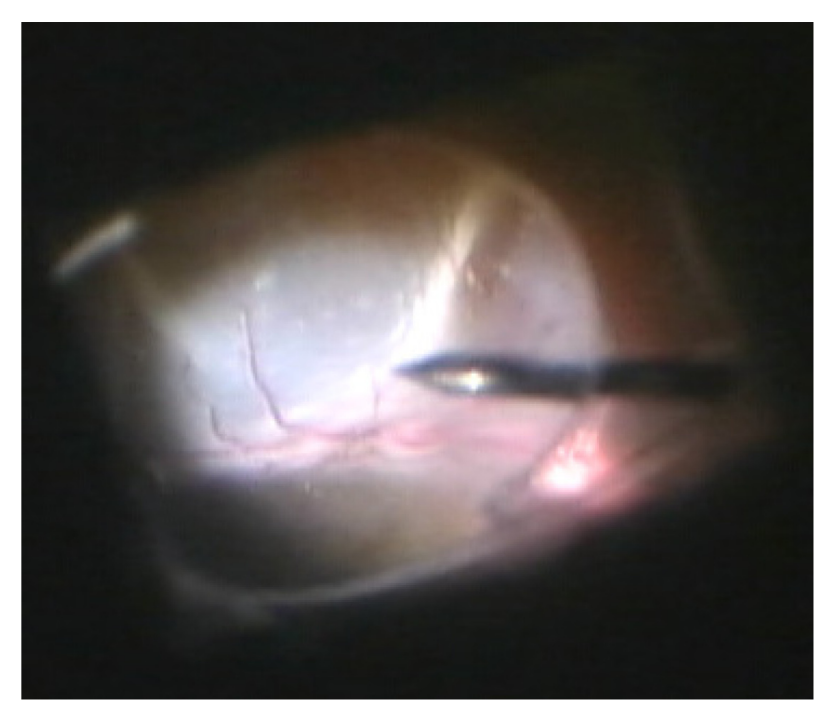

Figure 4 Intraoperative views during vitreous surgery.

Notes: The patient's left eye shows bullous retinal detachment with marked vitreous liquefaction. being caused by systemic collagen abnormality in Alagille syndrome. ${ }^{6}$ In this case, fragility of the zonule of Zinn may have caused subluxation of the intraocular lens. These findings suggest that collagen abnormality is present in various parts of the eye, including the zonule of Zinn, in patients with Alagille syndrome. Thus, surgeons should be careful when determining whether to perform intraocular lens implantation for cataract surgery in Alagille syndrome due to weakness of the zonule of Zinn. Moreover, abnormal vitreous liquefaction, in comparison with the patient's age, observed in this case may have caused the rapid progression of retinal detachment.

\section{Conclusion}

Ocular surgery in the case of Alagille syndrome reported in this present study was performed with a sufficient understanding of the anatomical characteristics as described above, and the postoperative serial observations were considered necessary.

\section{Disclosure}

The authors report no conflicts of interest in this work.

\section{References}

1. Turnpenny PD, Ellard S. Alagille syndrome: pathogenesis, diagnosis, and management. Eur J Hum Genet. 2012;20(3): 251-257.

2. Hingorani M, Nischal KK, Davies A, et al. Ocular abnormalities in Alagille syndrome. Ophthalmology. 1999;106(2):330-337.

3. Brodsky MC, Cunniff C. Ocular anomalies in the Alagille syndrome (arteriohepatic dysplasia). Ophthalmology. 1993;100(12):1767-1774.

4. Kim BJ, Fulton AB. The genetics and ocular findings of Alagille syndrome. Semin Opthalmol. 2007;22(4):205-210.

5. Wells KK, Pulido JS, Judisch GF, et al. Ophthalmic features of Alagille syndrome (arteriohepatic dysplasia). J Pediatr Ophthalmol Strabismus. 1993;30(2):130-135.

6. Traboulsi EI, Lustbader JM, Lemp MA. Keratoconus in Alagille's syndrome. Am J Ophthalmol. 1989;108(3):332-333.
Clinical Ophthalmology

\section{Publish your work in this journal}

Clinical Ophthalmology is an international, peer-reviewed journal covering all subspecialties within ophthalmology. Key topics include: Optometry; Visual science; Pharmacology and drug therapy in eye diseases; Basic Sciences; Primary and Secondary eye care; Patien Safety and Quality of Care Improvements. This journal is indexed on
PubMed Central and CAS, and is the official journal of The Society of Clinical Ophthalmology (SCO). The manuscript management system is completely online and includes a very quick and fair peer-review system, which is all easy to use. Visit http://www.dovepress.com/ testimonials.php to read real quotes from published authors. 